\title{
IDENTIFIKASI NYAMUK CULEX DAN AEDES AEGYPTI BETINA MENGGUNAKAN LINIER PREDICTIVE CODING DAN JARINGAN SYARAF TIRUAN LEARNING VECTOR QUANTIZATION
}

\author{
Achmad Lukman'), Wahju Tjahjo Saputro' ${ }^{2)}$ \\ ${ }^{1)}$ Teknik Informatika STMIK ELRAHMA, Jl. Sisingamangaraja No. 76 Yogyakarta \\ ${ }^{2)}$ Manajemen Universitas Muhammadiyah Purworejo, Purworejo Jawa Tengah \\ e-mail: mecaman@gmail.com ${ }^{1)}$,wahjusaputro@yahoo.com ${ }^{2)}$
}

\begin{abstract}
ABSTRAK
Pengolahan sinyal digital yang paling populer dan dampaknya positifnya cukup besar adalah bidang pengolahan suara digital.Pengolahan suara digital dapat dikembangkan dengan berbagai aplikasi yang dapat mempermudah kehidupan manusia, salah satu penelitian yang dapat dibuat adalah pengenalan suara nyamuk. Linier Predictive Coding (LPC) adalah proses mendapatkan nilai energi dalam sekelompok parameter orde LPC.

Dalam penelitian ini digunakan metode LPC untuk mengekstraksi ciri sinyal suara nyamuk Culex betina dan Aedes Aegypty betina berupa koefisien cepstrum yang didalamnya sudah terdapat frekuensi sinyal suara nyamuk agar dapat diklasifikasi dengan jaringan syaraf tiruan. Penelitian dilanjutkan dengan membuat sebuah perangkat lunak untuk menunjang eksperimen klasifikasi sinyal suara nyamuk sesuai dengan metode pengolahan sinyal yang diterapkan. Metode klasifikasi menggunakan jaringan syaraf tiruan learning vector quantization (LVQ). Pengujian ini dilakukan dengan skenario variasi jumlah orde LPC yaitu 8, 10, 12, 14 dan 16, dengan jumlah data pelatihan masing-masing nyamuk 50 ekor nyamuk dan pengujian 40 ekor.Selanjutnya hasil akurasi klasifikasi LVQ didapatkan untuk membuat kesimpulan pengaruh pemilihan orde $L P C$.
\end{abstract}

Kata kunci: $L P C$, LVQ, Culex betina, Aedes Aegypty betina

\begin{abstract}
Digital signalprocessing is the most popular andpositive impact big enough is the field of digital sound processing. Digital sound processing can be developed with awide range of applications which can facilitate human life, one of the research that can be made is the introduction of the sound of mosquitoes. Linier Predictive Coding (LPC) is the process of getting the energy value of the order parameter in a bunch of LPC.

In this study used a method pf LPC to extract characteristic signal sound mosquito Culex females and Aedes Aegypty females in it already, there is the frequency of the sound signals mosquitoes to be classified with neural network. Reaseach was continued by making a software support to the experiments the mosquito sound signal classification in accordance with the signal processing method are applied. Classification method using neural network Learning Vector Quantization (LVQ). This testing is done with the amount of variation order LPC scenario i.e. 8,10,12,14 and 16, with the amount of training data of each 50 mosquitoes and testing 40 mosquitoes. Furthermore the results accuracy classification LVQ obtained to make a conclusion the influence the selection order $L P C$.
\end{abstract}

Keywords: LPC, LVQ, Culex females, Aedes Aegypty females

\section{PENDAHULUAN}

$\mathrm{P}$ erkembangan teknologi dalam bidang ilmu komputer khususnya yang mempelajari tentang sinyal processing saat ini semakin banyak dan membawa dampak positif dalam kehidupan manusia.Salah satu disiplin ilmu dalam pengolahan sinyal digital yang paling populer dan dampaknya positifnya cukup besar adalah bidang pengolahan suara digital.

Pengolahan suara digital dapat dikembangkan dengan berbagai aplikasi yang dapat mempermudah kehidupan manusia.Salah satu aplikasi yang dapat dibuat adalah pengenalan suara nyamuk. Nyamuk adalah hewan kecil yang mempunyai banyak jenis, contohnya nyamuk culex pipens dan mansonia vektor cacing filariasis yang menyebabkan penyakit kuning, cikungunya dan penyakit infeksi lainnya, aedes yang merupakan vektor demam berdarah, dan anopheles yang merupakan vektor malaria [1]. Nyamuk mengeluarkan suara dengan kepakan sayapnya baik saat ingin mencari mangsa ataupun pada saat kawin.

Salah satu menjadi daya tarik penulis untuk melakukan penelitian klasifikasi suara nyamuk disebabkan karena penulis bermaksud mengetahui perbedaan suara nyamuk antara nyamuk aedes aegypti, nyamuk anopheles dan nyamuk culex pipiens. Hasil penelitian [2] bahwa kepakan sayap nyamuk aedes aegypti berada pada frekuensi $400 \mathrm{~Hz}$ sampai $600 \mathrm{~Hz}$ dan pada saat melakukan duet kawin bisa mencapai frekuensi $1200 \mathrm{~Hz}$ dan penelitian [3] yang menghasilkan frekuensi nyamuk Culex jantan yang terikat $542.4 \pm 81.60 \mathrm{~Hz}$ (rata-rata \pm standar deviasi; $\mathrm{n}=20$ adalah jumlah nyamuk setiap jenis kelamin ). Untuk culex betina yang terikat $428.3 \pm 42.92$ dan pada saat duet kawin bisa mencapai frekuensi $1200 \mathrm{~Hz}$ untuk harmonisasi frekuensi kedua jenis kelamin. 
Oleh karena itu penulis mengadakan sebuah penelitian klasifikasi beberapa jenis nyamuk dengan menggunakan teknik pengolahan sinyal dengan metode Mel Frequency Cepstral Coefficients.

\section{METODE}

\section{A. Prosedur kerja dan pengumpulan data}

\section{1) Prosedur kerja}

Penelitian ini penulis menyusun prosedur kerja untuk pengumpulan data suara nyamuk

1. Menyiapkan alat dan bahan

2. Setiap nyamuk didalam kandang diidentifikasi jenis kelaminnya dengan memasukkan seekor kelinci percobaan kedalam kandang nyamuk dan larutan gula pasir, jika nyamuk menggigit dan menghisap darah kelinci maka diidentifikasi jenis kelamin betina dan jika nyamuk hinggap dilarutan gula pasir maka diidentifikasi jenis kelamin jantan.

3. Mengambil nyamuk diidentifikasikan jenis kelamin betina dengan memakai alat aspirator secara perlahan dan menjaga agar nyamuk tidak mengalami stress, jika nyamuk mengalami stress pada saat perekaman nyamuk langsung pingsan dan mati.

4. Menempatkan nyamuk satu persatu kedalam botol kecil yang ditutupi kain kasa yang telah dilengkapi microphone didalamnya.

5. Melakukan perekaman satu nyamuk satu proses perekaman.

\section{2). Pengumpulan data}

1. Nyamuk yang telah ditempatkan di botol kecil kemudian direkam suara dengungannya selama 2 detik satu persatu dengan menggunakan software CoolEditpro 2.0. setelah perekaman selesai nyamuk dilepas kembali kekandang lain yang menandakan nyamuk tersebut telah direkam suaranya.

2. Suara nyamuk berupa file wav yang telah direkam dikumpulkan tiap jenis dalam satu folder suara yang bernama DataNyamuk. Setiap data suara nyamuk dibersihkan dari noise berupa suara latar yang tidak diiinginkan dengan menggunakan software CoolEditpro 2.0 sehingga benar-benar didapatkan suara nyamuk yang diinginkan.

3. Pengumpulan data selesai.

\section{B. Analisis dan Rancangan Sistem}

Ada dua tahapan proses utama dalam klasifikasi nyamuk berdasarkan suaranya yang dibangun dalam penelitian ini, yakni tahapan pelatihan dan tahapan pengujian. Tahapan pelatihan adalah tahapan untuk melatih atau mengajari sistem untuk mengenali pola umum setiap jenis suara nyamuk. Sedangkan tahapan pengujian adalah tahapan untuk mengetahui kemampuan pengenalan yang dapat dilakukan oleh sistem berdasarkan tahapan pelatihan yang dilakukan. Kedua tahapan proses dalam sistem ditunjukkan dalam bentuk bagan alir sistem pada Gambar 1 dan 2 .
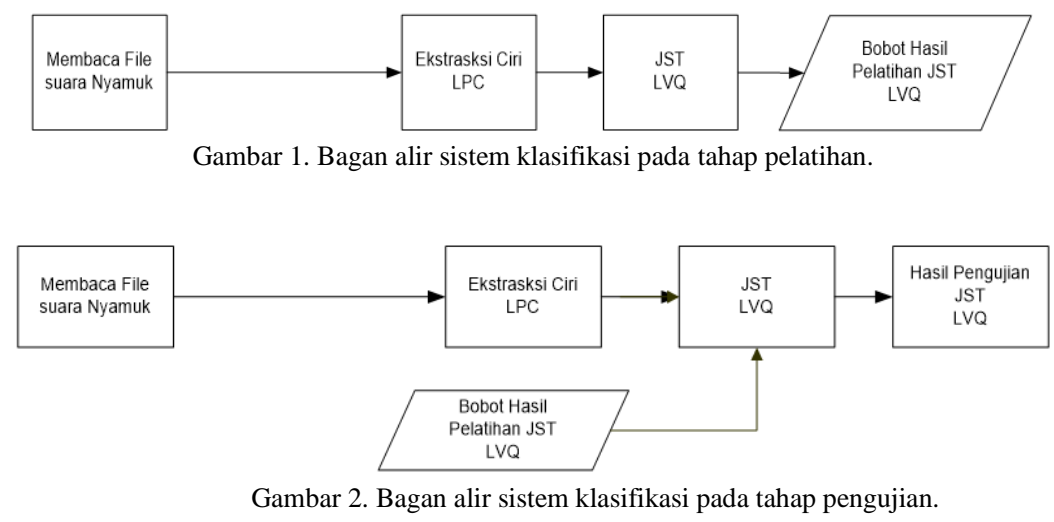

Proses - proses pada tahapan pelatihan dan urutan proses dapat dilihat pada Gambar 1. Proses pelatihan diawali dengan proses membaca berkas suara nyamuk dan diakhiri dengan proses pelatihan dengan jaringan saraf tiruan. Proses membaca berkas suara nyamuk menghasilkan sinyal digital suara nyamuk yang akan diteruskan ke proses ekstraksi ciri Linier Predictive Coding (LPC). Pada proses LPC pertama-tama melalui proses pre-emphasis sinyal suara nyamuk difilter atau diperbaiki efek gangguan suara latar yang diakibatkan pada saat proses perekaman suara nyamuk di dalam laboratorium. Hasil dari proses pre-emphasis akan dikirim ke proses frame blocking, windowing, autokorelasi, analisis LPC dan koefisien cepstral LPC sehingga menghasilkan koefisien ciri yang jumlahnya sesuai dengan variasi jumlah orde LPC. Hasil ekstraksi ciri menjadi data representatif dari sinyal suara nyamuk dan digunakan sebagai masukan pada jaringan syaraf tiruan. Jaringan syaraf tiruan yang akan digunakan dalam pelatihan ini adalah jaringan syaraf tiruan Learning Vector Quantization (LVQ) sehingga menghasilkan bobot hasil. 


\section{Ekstraksi Ciri dengan LPC}

Tujuan dari extraksi LPC secara umum untuk mengambil koefisien LPC, dimana didapatkan berdasarkan nilai orde LPC antara 8 sampai 16. Pada proses ini Sinyal suara di ekstraksi cirinya dengan beberapa proses yang terlihat seperti Gambar 3.

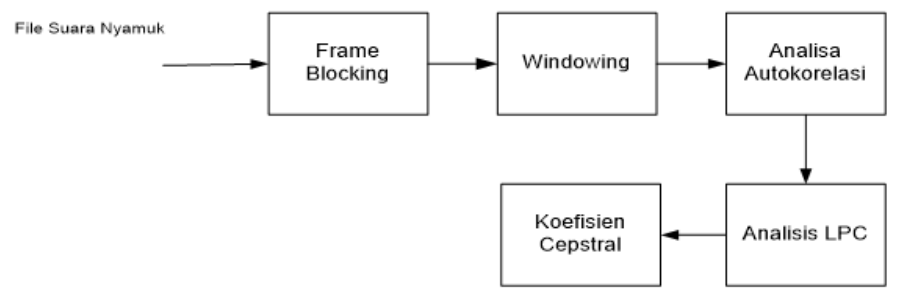

Gambar 3. Blog Diagram LPC.

Berdasarkan blog diagram Gambar 3 file suara berupa sinyal suara nyamuk diproses pertama-tama dengan proses frame Blocking [4] yang dijelaskan pada sub pokok bahasan Frame Blocking.

\section{1). Frame Blocking}

Hasil dari proses pre-emphasis kemudian dipotong-potong menjadi beberapa potongan kecil, setiap potongan tersebut disebut frame. Jumlah data dalam satu frame (N) berisi 512 buah. Sedangkan jarak antar frame (M) adalah 200 buah. Sehingga, jumlah frame (L) untuk data sebanyak 4000 (nilai ini diambil setengah dari frekuensi sampling) dapat dihitung dengan $\mathrm{L}=($ data- $(\mathrm{N}-\mathrm{M})) / \mathrm{M}=(4000-(512-200)) / 200=18$ buah frame. Sehingga didapatkan hasil sejumlah banyak frame $(\mathrm{L}) *$ banyak data dalam satu frame $(\mathrm{N})=18 * 512=9216$ buah. Potongan frame digambarkan seperti Gambar 4.

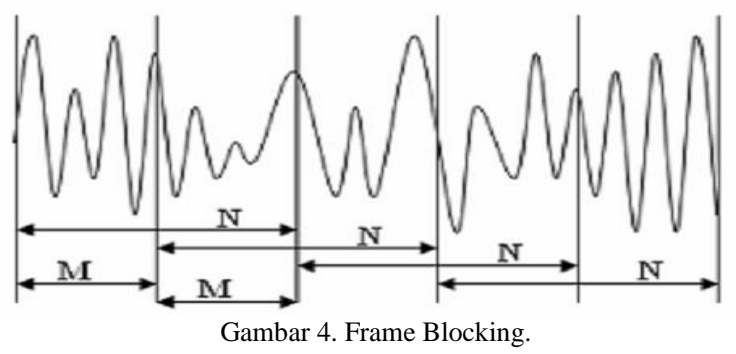

\section{2). Windowing}

Window yang dipakai pada penelitian ini adalah Window Hamming. Proses window ini berfungsi untuk mengurangi diskontinyu pada ujung-ujung frame akibat dari proses framing seperti terlihat pada Gambar 5 .

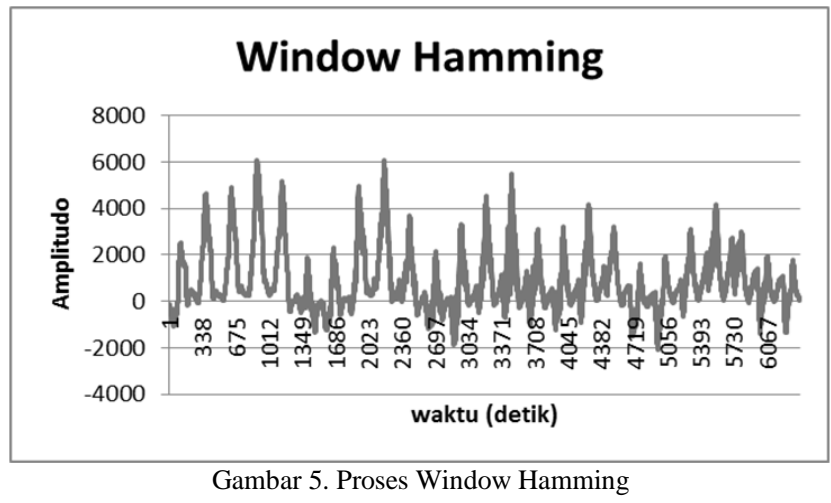

Dengan menggunakan rumus diperoleh hasil sebagai berikut:

$$
w_{0}=0.54-0.46 \cos \left(\frac{2 * a \cdot 14 * 0}{512-1}\right)=0.08
$$

untuk data hasil frame blocking yaitu $(-1111.94,53.13,258.13,405.15,531.72,181.12,557.57,448.79)$

sehingga, $w_{0}=0.08 *(-1111.94)=-1.77$

Dengan cara yang sama dilakukan untuk data sampel yang lain, dan diperoleh nilai hasil windowing $(-88.99,4.258,20.73117,32.6373,42.99,14.716,45.555,36.9011)$.

\section{3). Analisa Autokorelasi}

Pada tahap ini masing-masing frame yang telah di windowing diautokorelasikan untuk mendapatkan [5] : 


$$
\eta_{1}(m)=\sum_{n=0}^{W-1-m} X_{l}(n) X_{1}(n+m)
$$

dimana nilai autokorelasi yang tertinggi pada $m=p$ adalah orde dari analisa LPC, biasanya orde LPC tersebut 8 sampai 16. Autokorelasi ke-0 melambangkan energi dari frame yang bersangkutan dan ini merupakan salah satu keuntungan dari metode autokorelasi.Pada penelitian ini akan diambil orde LPC sebanyak 5 buah yaitu 8, 10, 12, 14 dan 16.

\section{4). Analisis $L P C$}

Langkah selanjutnya adalah analisa LPC, dimana pada tahap ini $p+1$ autokorelasi pada setiap frame diubah menjadi satu set LPC parameter yaitu koefisien LPC, koefisien pantulan (reflection coefficient), koefisien perbandingan daerah logaritmis (log area ratio coefficient). Salah satu metode untuk melakukan hal ini ialah metode Durbin yang dinyatakan dalam algoritma dibawah ini :

$$
\begin{aligned}
& E^{(0)}=r(0) \\
& k_{i}=\frac{\left\{r(i)-\sum_{j=1}^{i}-1 \alpha_{j}^{(i-1)} r([i-j \mid])\right.}{E^{(i-1)}}, 1 \leq i \leq p \\
& \alpha_{i}^{(i)}=k_{i} \\
& \alpha_{i}^{(i)}=\alpha_{j}^{(i-j)}-k_{i} \alpha_{i-j}^{(i-1)}, 1 \leq j \leq i-1 \\
& E^{(i)}=\left(1-k_{i}^{2}\right) E^{(i-1)}
\end{aligned}
$$

Persamaan diatas direkursi untuk $i=1,2, \ldots, p$ dan penyelesaian akhirnya berupa :

$$
\begin{aligned}
a_{m} & =\text { koefisien LPC }=\alpha_{m}^{(p)}, 1 \leq m \leq p \\
k_{m} & =\text { koefisien PARCOR (koefisien pantulan) } \\
g_{m} & =\text { koefisien perbandingan daerah logaritmis } \\
& =\log \left(\frac{1-k_{m}}{1+k_{m}}\right)
\end{aligned}
$$

\section{5). Koefisien Cepstral}

Sekumpulan LPC parameter dapat dihasilkan dari penurunan koefisien LPC yang merupakan koefisien cepstral $c(m)$. Persamaan yang digunakan untuk menghitung koefisien cepstral ini ialah:

$$
\begin{aligned}
& c_{(m)}=a_{m}+\sum_{k=1}^{m-1}\left(\frac{k}{m}\right) c_{k} a_{m-k}, 1 \leq m \leq p \\
& c_{(m)}=\sum_{k=1}^{m-1}\left(\frac{k}{m}\right) c_{k} a_{m-k}, m>p
\end{aligned}
$$

Koefisien cepstral ini adalah koefisien transformasi Fourier yang merepresentasikan spektrum log magnitude. Koefisien cepstral ini yang digunakan sebagai inputan untuk mengklasifikasi jenis nyamuk yang akan diteliti.

6). Jaringan Syaraf Tiruan $L V Q$

Arsitektur jaringan syaraf tiruan LVQ [6] yang dibangun pada penelitian ini seperti terlihat pada Gambar 6.

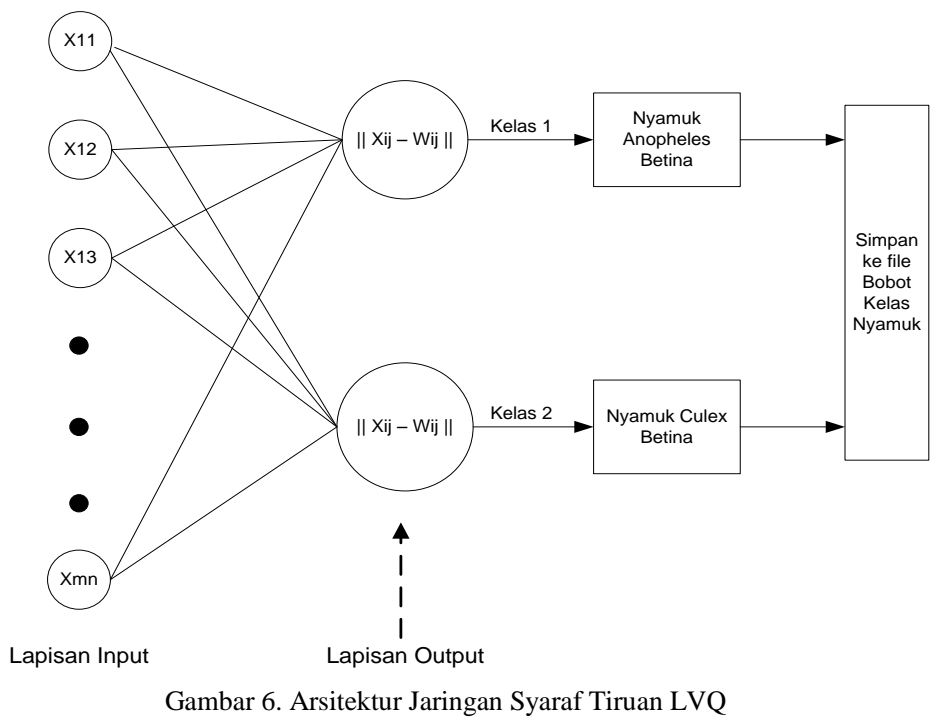

Gambar 6 merupakan arsitektur jaringan syaraf tiruan LVQ dengan 2 lapisan (layer), yaitu 1 lapisan input berupa

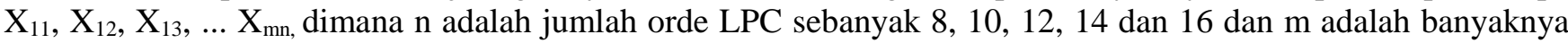
data sinyal suara nyamuk. Selanjutnya 1 lapisan output dengan 2 keluaran yaitu $\mathrm{Y}_{1}$ untuk nyamuk Anopheles dan $\mathrm{Y}_{2}$ untuk nyamuk culex. 


\section{7). Confusion Matrix}

Confusion matrix disebut juga matriks klasifikasi yang menjadi suatu alat visual dalam supervised learning [9]. akurasi $=\frac{T P+T N}{T P+T N+F P+B F N}$

Akurasi dari klasifikasi dapat diperoleh dari penjumlahan true positif dan true negatif dibagi total untuk melihat kinerja secara keseluruhan.

\section{HASIL DAN PEMBAHASAN}

Pengukuran unjuk kerja dari sistem klasifikasi nyamuk berdasarkan suaranya dengan mencari persentase kesalahan pencocokan yang menyatakan probabilitas terjadinya kesalahan pada sistem. Pada pengujian ini penulis menggunakan 2 jenis nyamuk yaitu aedes aegypti dan culex betina dengan masing-masing 50 sampel suara untuk pelatihan dan masing-masing 40 sampel suara untuk pengujian.

Penelitian ini bertujuan untuk melakukan eksplorasi Perbandingan parameter-parameter jaringan syaraf tiruan terhadap variasi jumlah orde LPC berpengaruh terhadap hasil klasifikasi sinyal suara nyamuk.

\section{Perbandingan Parameter-Parameter LVQ Terhadap Variasi Orde LPC}

Sebelum melakukan pengujian terhadap pengaruh jumlah orde LPC pada jaringan syaraf tiruan, maka dilakukan perbandingan parameter-parameter pada jaringan syaraf tiruan yang dipakai pada penelitian ini yaitu LVQ. Pengujian parameter yang dilakukan pada parameter LVQ adalah untuk mencari learning rate yang paling optimal, hasil pengujian akan diperlihatkan pada Tabel I.

TABEL I

HASIL PERBANDINGAN PENGUJIAN TERHADAP TOLERANSI ERROR 0.001

\begin{tabular}{|c|c|c|c|c|c|c|}
\hline \multirow{2}{*}{$\begin{array}{l}\text { Learning } \\
\text { Rate } \\
(\alpha)\end{array}$} & \multirow{2}{*}{$\begin{array}{c}\text { Hasil Pelatihan } \\
\text { epoch }\end{array}$} & \multicolumn{5}{|c|}{ Hasil Pengujian } \\
\hline & & $\begin{array}{l}\text { Akurasi Data Uji } \\
\text { Orde LPC } 8(\%)\end{array}$ & $\begin{array}{l}\text { Akurasi Data Uji } \\
\text { Orde LPC } 12(\%)\end{array}$ & $\begin{array}{l}\text { Akurasi Data Uji } \\
\text { Orde LPC } 14(\%)\end{array}$ & $\begin{array}{l}\text { Akurasi Data Uji } \\
\text { Orde LPC } 14(\%)\end{array}$ & $\begin{array}{l}\text { Akurasi Data Uji } \\
\text { Orde LPC } 16(\%)\end{array}$ \\
\hline 0.001 & 22 & 65.83 & 67.50 & 69.16 & 73.33 & 72.50 \\
\hline 0.01 & 22 & 72.50 & 82.00 & 71.44 & 70.11 & 69.33 \\
\hline 0.1 & 66 & 73.33 & 80.00 & 74.16 & 73.33 & 63.33 \\
\hline 1 & 88 & 33.33 & 33.33 & 33.33 & 33.33 & 33.33 \\
\hline
\end{tabular}

Hasil pengujian pada Tabel I menunjukkan bahwa nilai learning rate membutuhkan waktu yang relatif cepat sehingga memperlihatkan hasil pengujian yang paling optimal didapatkan pada learning rate 0.01 pada jumlah orde LPC 12 dengan nilai akurasi $82 \%$.

\section{SIMPULAN DAN SARAN}

Berdasarkan uraian hasil dan pembahasan dapat disimpulkan bahwa :

1) Hasil pengujian klasifikasi suara jenis 3 nyamuk memperlihatkan optimal pada jumlah orde LPC 12 dan berkurang seiring dengan penambahan jumlah orde LPC.

2) Hasil pengujian klasifikasi jaringan syaraf tiruan dengan learning vector quantization menghasilkan nilai akurasi klasifikasi yang paling tinggi 82.5\% pada jumlah orde LPC 12.

Rencana penelitian kedepan untuk meningkatkan sistem klasifikasi nyamuk berdasarkan suaranya ada beberapa metode yang dapat diterapkan

1) Microphone yang sangat senstitif dan ruang yang sangat tenang dapat membantu pengambilan suara nyamuk sehingga perlu dipikirkan untuk penelitian selanjutnya.

2) Pembuatan perangkat keras elektronika khusus untuk proses mendukung penelitian klasifikasi nyamuk berdasarkan suaranya.

\section{REFERENSI}

[1] Suwito, A., 2007, Keanekaragaman jenis nyamuk (Diptera: Culicidae) yang dikoleksi dari tunggul bambu Taman Nasional Gn. Gede-Pangrango dan Taman Nasional Gn. Halimun. Zoo Indonesia. Vol. 16 (1): 31-47

[2] Warren, B., Gibson, G.,Russel J.I., 2009. Sex recognition through Midflight Mating Duets in Culex Mosquitoes.Current Biology 19. March 24, 2009.

[3] Lauren J. C., Ben J. A., Laura C.H., and Ronald R. H., harmonic convergence in the love songs of the Dengue Vector Mosquito, Published Online 8 January 2009 Science 20 February 2009:Vol. 323 no. 5917 pp. 1077-1079 DOI: 10.1126/science.

[4] Afriany, S.S., Suryani, E., Wiharto., 2013. Pengenalan Nada Pada Senar Biola Dengan Metode Jaringan Saraf Tiruan Learning Vector Quantization. SENTIKA 2013. ISSN: 2089-9815.

[5] Dave, N., 2013. Feature Extraction Methods LPC, PLP and MFCC in Speech Recoginition. International Journal For Advance Research in engineering and Technology. Volume 1, Issue VI, juli 2013.

[6] Fausset, L., 1994, Fundamentals of Neural Networks, Architecture, Algorithms and Application, Prentice-Hall. 